\title{
Colmena post-digital. Sistema de acceso abierto para aportes y visualización de bases de datos colaborativas.
}

Post-digital Hive. Open Access System for contributions and visualization of collaborative data bases.

\author{
> Maria Elena Tosello \\ Universidad Nacional del Litoral, Argentina. \\ mtosello@fadu.unl.edu.ar
}

\author{
> Luis Enrique Carrara \\ Universidad Nacional del Litoral, Argentina. \\ luis.e.carrara@gmail.com
}

\begin{abstract}
The collective and multidirectional production and dissemination of ideas, texts, images, etc., suppose virtual interactive devices and environments that host and potentiate exchanges, starting from trans-media narratives. Related to the processes of culture digitalization and collaborative construction of knowledge, an immense quantity of digital productions condenses the educative, scientific and artistic heritage of humanity. These productions semantically gather configuring data bases. Hive is an open source-open access system which allows creating, managing and visualizing collaborative data bases of multimedia resources, to apply in educative spaces, libraries, public or private institutions, or for individual purposes.
\end{abstract}

Keywords: Software libre; Bases de datos; Espacio-interfaz; Narrativa transmedial; Tecnologías ubicuas

\section{Introducción}

En la era post-digital, los espacios virtuales interactivos son construidos y experimentados colectivamente a partir de una multiplicidad de palabras, imágenes, videos y otras producciones que surgen de miles de usuarios individuales y de redes sociales o educativas con intereses comunes, que se actualizan en una diversidad de localizaciones y circunstancias, y se visualizan a través de diferentes artefactos, por lo cual la posibilidad de crear y compartir bases de datos-BD- es indispensable para una comunicación y colaboración efectivas.

Machado (1996) vislumbró que la escritura confundida con la lectura tendería a tornarse colectiva, ya que los hipermedios son sistemas esencialmente interactivos; y que la hipermedialidad reconfiguraría al texto y la lectura a partir de la organización no-lineal, la fragmentación y la metáfora de la navegación; reconfiguraría al autor mediante experiencias de escritura colaborativas; y reconfiguraría a la narrativa, desde la crisis de la concepción aristotélica del relato clásico: principio, desarrollo y fin, junto a la temporalidad y la idea de unidad (Rodríguez Barros, 2012: 88).

Desde la perspectiva de la experiencia del sujeto, todos los objetos del ambiente digital son $\mathrm{BD}$, colecciones de elementos en las que se puede navegar, buscar, aportar o editar. Los sitios en Internet son $\mathrm{BD}$, listas de elementos independientes en las cuales "siempre es posible ańadir un nuevo elemento". La naturaleza abierta de la Red engendra sitios dinámicos que siempre están creciendo, lo cual contribuye a la lógica antinarrativa de la web (Manovich, 2006: 286). La Red estimula un proceso de expansión comunicacional multidireccional que genera un cruce de narraciones, obras tridimensionales dotadas de estructuras dinámicas que las vuelven manipulables interactiva y colectivamente; obras abiertas y polisémicas en continua transformación donde ninguna relación es definitiva (Schultz, 2006); poemas-constelación configurados como acontecimientos tridimensionales, destinados a representar el cambio, simultáneos, instantáneos y eternamente mutantes (Machado, 1996).

Según Manovich, una colección de elementos y un espacio por el que circular o navegar son las formas culturales usuales que representan la experiencia humana en los nuevos medios -NM-. La BD se emplea para almacenar todo, permite la organización y el acceso a los objetos digitales a partir de la indexación múltiple; y el espacio virtual tridimensional e interactivo permite el desplazamiento y la visualización de los contenidos. Se podría definir a la base de datos como la forma simbólica de la sociedad informatizada, un nuevo modo de entender la experiencia espacio-temporal en un mundo que se presenta como una colección interminable -y aparentemente desestructurada- de imágenes, textos y otros registros de datos de igual jerarquía, que demanda una estética y una ética específicas (Manovich, Óp.Cit.: 284). El hecho de que todos los elementos de una $\mathrm{BD}$ tengan la misma jerarquía, provoca un aplanamiento de los datos que privilegia el espacio frente al tiempo, una "espacialización" que tiende a desnarrativizar todas las representaciones y experiencias, razón por la cual el procedimiento apropiado para crear una BD, es distribuir los elementos en el espacio (Î́dem: 306). La creación de obras en los NM se reduce entonces a dos acciones proyectuales: la construcción de interfaces adecuadas a BD multimediales y la 
definición de métodos de navegación a través de representaciones espaciales (Ídem: 280).

Además de proporcionar una base fundamental para la estética de los NM, "el espacio navegable puede entenderse como un tipo particular de interfaz a una BD”, la evolución desde una red de datos abstractos a "una Internet 'perceptualizada', donde los datos han sido sensualizados”. La visualización espacializada de objetos digitales es una forma nueva y exclusiva de los NM, en donde por primera vez el espacio se convierte en un tipo de medio que puede ser transmitido, almacenado y recuperado; comprimido, reformateado, convertido en un flujo continuo, computado y programado, y se puede interactuar con él (Ídem: 318-320).

El espacio del conocimiento, siempre inasequible, móvil, vivo, múltiple, está animado por las navegaciones de los colectivos que lo recorren y que usan la imaginación para buscar nuevas formas de comunicación y ensanchar la apertura y humildad que permiten el aprendizaje. Es el lugar de la autoinvención constante de las comunidades humanas, es el puente entre los hombres divididos que permite coexistir la diversidad (Lévy, 2004: 134). El espacio del saber se despliega en entornos virtuales humanizados que incentivan la filosofía del compartir y la participación en la construcción colaborativa de los conocimientos a través de tecnologías de Acceso Abierto -AA-, acoplándose a la Comunidad de las Humanidades Digitales (http://tcp.hypotheses.org/487) y al Movimiento para la Educación Abierta (http://www.capetowndeclaration.org), los cuales tienen el potencial para provocar un cambio significativo en los estándares mundiales de educación, combinando la capacidad comunicacional de Internet con la reutilización y recontextualización de objetos digitales educativos para lograr una real democratización del conocimiento, sustentada en valores de accesibilidad plena, inclusiva y plural (San Martín, 2010).

La transformación de los medios de comunicación discursivos en medios participativos puede ser considerada como un punto de inflexión cultural, pero una revolución epistemológica, estética y ética no depende sólo de la tecnología y del flujo de información que circula, sino de la comunicación interpersonal y del acceso sin restricciones a los medios, creando nuevos modelos que propongan una reinterpretación de la producción de conocimientos en la Red. La noción de polifonía y los fundamentos filosóficos, estéticos y estructurales del "modelo carnaval" en el sentido asignado por Bajtín pueden servir de inspiración teórica para definir un modelo de la cultura de los NM y de la estética del arte en la Red (Giannetti, 1999).

Bajtin concibe al carnaval como una experiencia social situada en el umbral entre el arte y la vida (Ídem) que implica una percepción diferente del mundo, que posee una poderosa fuerza vivificante y transformadora, que suspende la norma unívoca, monológica, dogmática y enemiga del cambio, suspensión que tiene consecuencias institucionales y políticas; y goza del protagonismo del pueblo que en forma multitudinaria personifica el caos mediante la alteración de los órdenes y roles sociales, configurando un mundo de infinitas manifestaciones que anula las jerarquías establecidas y celebra la ambivalencia.

El mundo del carnaval es una construcción colectiva cuyos rasgos más significativos en relación a la Red son: un modo de convivencia que diluye las estructuras jerárquicas y propone una comunicación en red, abierta, plurimedial y ramificada que va creciendo de forma aparentemente caótica con la progresiva integración de personas que se envuelven en su trama -sin reglas de acceso-, a partir de la experiencia y la libre invención; una deliberada heterogeneidad de estilos y voces que niegan la unidad y proponen la mezcla, el remix y el montaje, todo lo desunido y distanciado por la visión jerárquica entra en contacto y se interrelaciona de manera creativa, participativa, activa y fragmentaria; la relatividad de las verdades dominantes del poder, una visión del mundo y las relaciones humanas deliberadamente no-oficial, opuesta a la pretensión de inmutabilidad que se manifiesta en formas de expresión dinámicas, fluctuantes y activas; un lugar sin fronteras espaciales similar al campo de datos de la Red, un sistema complejo, abierto y pluridimensional en el que los usuarios desempeñan un papel fundamental, de carácter dinámico, potenciado por el acceso libre a la información, que permite la superación de la unidimensionalidad del lenguaje analógico y los modelos occidentales de centralidad y secuencialidad del discurso (Giannetti, Óp.Cit.: 22-23); la relatividad como principio estético, sus expresiones manifiestan la ruptura de los límites de la estética posmoderna y neobarroca, y como el hipermedio, se abren a una polifonía textual estableciendo relaciones que borran las jerarquías semióticas, narrativas y políticas, mostrando una gran predisposición a la interpenetración de hilos dialógicos, porque para comprender la historia no solo hay que borrar las fronteras entre las disciplinas, sino también las jerarquías entre los niveles del discurso. Son historias de fronteras a ser cruzadas que se encuentran en la actualidad del arte contemporáneo, donde todas las competencias artísticas tienden a salir de su propio dominio y a intercambiar sus lugares y poderes, una hibridación de los medios del arte apropiada a la realidad posmoderna de lo real y lo virtual, de lo orgánico y las prótesis mecánicas o informáticas (Rancière, 2010:26-27).

El potencial creativo de los sistemas de AA, cuyo propósito es el enriquecimiento mutuo de las personas y la movilización de sus competencias, debe ser coordinado en tiempo real a través de dispositivos de comunicación que ofrezcan a los miembros de una comunidad los medios para conjugar sus aportes y acciones en un universo transdisciplinar de conocimientos, acontecimientos y sujetos que alimentan continuamente un paisaje móvil de significaciones e interpretaciones variables (Lévy, Óp.Cit.: 20), un inmenso mar de textos que se transforman, relacionan y navegan simultáneamente. Todo ser humano si es atento puede aprender a navegar, pero incluso en el mar que cuenta con el sol y las estrellas, la navegación sin instrumentos sería imposible (Lynch, 1984: 15).

Un dispositivo hipermedial dinámico integrado a la vida cotidiana podría reunir y coordinar todo: producciones culturales, sujetos y tecnologías, ya que para organizar y gestionar la complejidad es indispensable una representación simultánea en múltiples niveles de articulación que posibilite interacciones multidireccionales. El sistema Colmena, como manifestación de la red de conexiones de un universo virtual de conocimientos, no tiene límites, fluye hacia el infinito, es volátil y ambiguo, necesita ser recorrido como un laberinto, es mapa y territorio (Montagú, Groisman, Pimentel, 2004: 49). 


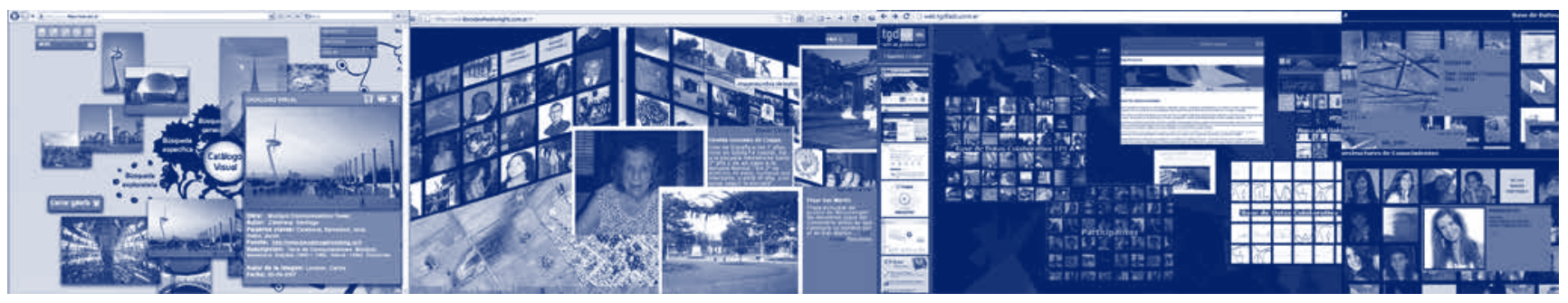

Figura 1: Izq.: Biblioteca Virtual FADU-UNL. Centro: Libro Hipermedial de la Memoria de Wheelwright. Der.: Web del Taller de Gráfica Digital.

\section{Metodología y Materiales}

Si bien en Internet existen sistemas para guardar y compartir información, éstos presentan limitaciones en cuanto a la gestión y visualización de algunos tipos de archivos, por ejemplo las páginas web. Además, el teletrabajo colaborativo requiere poder editar, indexar y describir los archivos compartidos para poder recuperar los datos en forma sencilla y eficiente. Los servicios disponibles -como Google Drive o Dropbox- no posibilitan indexar y describir los contenidos, ni integrar aplicaciones, y solo permiten la edición de textos, presentaciones y planillas de cálculo. Otra limitación que presentan se vincula a la distribución espacial, ya que se accede a los archivos en espacios compartimentados que se organizan en una estructura jerárquica de árbol con directorios independientes, y se navegan secuencialmente, desaprovechando la capacidad de simultaneidad y multitarea del ambiente virtual.

Los artefactos y sistemas artificiales pueden caracterizarse en términos de funciones, objetivos y adaptación. La adecuación de las soluciones de diseño a las necesidades de los usuarios implica una relación entre el propósito, el carácter del sistema y el entorno en el que actúa (Simon, 2006: 10). Abordar la producción de un sistema complejo, teniendo en cuenta la interdependencia entre los componentes, implicó un proceso de diseño en el cual primero se generaron alternativas, y luego éstas se comprobaron mediante instancias de experimentación, una serie de ciclos de generación y prueba para evaluar y ajustar la propuesta.

Una herramienta teórica útil que permitió vincular el diseño conceptual, la formulación de relaciones problema-solución y el desarrollo del sistema, es el "marco socio-técnico"-MST- el cual incluye: análisis, diagnóstico, costumbres y valores socio-culturales, premisas estéticas y funcionales, conocimientos científicos, posibilidades tecnológicas, procesos de testeo, etc. El MST es interdisciplinario y dinámico, incluye componentes heterogéneos y múltiples dominios cognitivos e integra procesos interactivos de apropiación social de tecnologías (Thomas \& Buch, 2008: 236).

Colmena integró desarrollos anteriores: la Biblioteca Virtual FADU, el Libro Hipermedial de la Memoria y la web TGD (Fig. 1), incorporando mejoras y nuevas funcionalidades. El sistema completo se organizó a partir de bloques de programas, acoplando módulos o desarrollos parciales a la estructura principal para cumplir funciones específicas. Por ejemplo highslide, que es un software en JavaScript que permite la visualización simultánea de imágenes y demás recursos del sistema.
Un aspecto del desarrollo de este sistema y que en general caracteriza los procesos de configuración de estilos locales de innovación tecnológica en Latinoamérica, es la "resignificación de tecnologías", que implica la reutilización creativa de tecnologías, conocimientos, habilidades, artefactos y sistemas disponibles, y su adecuación a condiciones locales, estableciendo relaciones usuario-diseñador-programador y dinámicas de resolución de problemas particulares. No son meras modificaciones de tecnologías, sino una reasignación de su sentido y medio de aplicación que permite mapear procesos de rediseño con significados construidos localmente, e iniciar procesos de construcción de funcionamiento y utilidad de tecnologías con la participación de sus actores locales (Ídem: 255).

Simon plantea que la innovación puede consistir en una "combinación" nueva de interacciones entre los componentes de un sistema, definidos en términos de su rol en el funcionamiento del todo organizado (Simon, Óp. Cit.). La combinación de tecnologías es un tipo de "metamorfosis" que se produce cuando se integran dos o más elementos disímiles. La metamorfosis que más desafía al productor es el "cambio de dominio", que significa utilizar una herramienta o sistema con una finalidad diferente o para una actividad distinta a la original, como ocurrió con este sistema.

\section{Resultados}

Colmena es un sistema de código y AA que permite crear, administrar y visualizar bases de datos colaborativas. Fue desarrollado inicialmente para el ámbito educativo pero puede utilizarse para configurar y visualizar archivos de bibliotecas, instituciones públicas o privadas, y también para su apropiación a nivel individual. El sistema integra herramientas de software de dominio público, constituyendo un dispositivo sencillo y atractivo que habilita a:

- crear, compartir y visualizar en forma simultánea bases de datos de textos, imágenes, sonidos, videos, páginas web y otros tipos de archivos almacenados en la nube;

- - indexar o "etiquetar", describir y editar colaborativamente los objetos de las BD;

- - definir categorías temáticas y establecer relaciones semánticas entre recursos de distintas categorías o BD;

- - incorporar múltiples servicios web como facebook, youtube, skype, prezi, flickr, etc.;

- $\quad$ - personalizarse, adaptándose a las necesidades de usuarios con diversos perfiles y contextos.

El sistema está desarrollado utilizando herramientas open source o de código abierto, lenguaje de programación PHP5 y MySQL como gestor de base de datos, y fue probado y optimizado en un servidor web Apache. Inicialmente el proyecto se abordó con programación lineal, pero a medida que el sistema se fue 
complejizando se optó por trabajar con un entorno o framework de desarrollo: Codeigniter y YII. Estos entornos siguen el concepto "modelo, vista, controlador" -MVC- de manera de independizar el código en: Lógica (controlador), Acceso a datos (modelo) y Diseño de interfaz (vista).

\section{Usuarios y roles}

Posteriormente al análisis y evaluación de varias extensiones, y se optó por incorporar al sistema la que administra usuarios y roles de modo más completo. Es una extensión desarrollada externamente que además de manejar el registro y autenticación de los usuarios, permite asignarles roles y tareas, agrupándolos en categorías. Estos roles suponen diferentes permisos, definiendo niveles de jerarquía o responsabilidad para la operatividad del sistema. Cada perfil de usuario, acorde a su rol, tendrá acceso a una interfaz particular, que le permitirá operar y configurar las posibles interacciones con el sistema.

Las categorías establecidas son: super-administrador, que se asigna a quien instala el sistema o alguien designado por él, y es el único con acceso al servidor y al código fuente; administradores, que harán todas las tareas necesarias para adaptar el sistema a aplicaciones particulares, a través de la interfaz (sin acceso a código); y usuarios básicos. En el caso de aplicaciones educativas los administradores podrían ser los docentes, quienes tendrán los permisos necesarios para definir las tablas y campos de la $\mathrm{BD}$, y los tipos de recursos que estarán disponibles para todos los usuarios del sistema. Los alumnos pueden personalizar el espacio-interfaz de la aplicación modificando los servicios y accesos de los menús, además de los aspectos visuales (imagen de fondo, colores, etc.). Estas capacidades de personalización y modificación están disponibles para todos los roles.

Todos los recursos, además de una descripción textual, poseen una representación visual. Si el recurso que se incorpora a la BD no es una imagen, el sistema permite acoplar un segundo archivo como imagen del recurso. A través del etiquetado de los elementos de la $\mathrm{BD}$ se logra ampliar enormemente la capacidad de visualización

Figura 2: Diagrama operativo del dispositivo hipermedial que incluye BD, recursos, relaciones y participantes. de los contenidos, brindando alternativas de recuperación de la información a partir del sistema de búsqueda.

Colmena incorpora un sistema de "hilos" que permite visualizar dinámicamente las relaciones entre los recursos. En función a este objetivo, en la ficha de carga se muestran los campos que permiten a establecer las relaciones entre las categorías. Esta capacidad relacional representa la mayor diferencia de este sistema en relación a otras aplicaciones que organizan los recursos en carpetas separadas, como el explorador de archivos de Windows.

\section{Experiencias realizadas}

El sistema, que se desarrolló entre 2009 y 2014 en el marco de la tesis doctoral "El espacio-interfaz del Dispositivo Hipermedial Dinámico", constituye un instrumento útil para aplicar en estrategias didácticas innovadoras, a partir de la construcción de bases de datos colaborativas cuyos recursos podrán ser aportados por los alumnos, y su visualización, en un espacio sin jerarquías rizomático, polifónico y mutable. Se testearon diversos prototipos experimentales parciales: en el taller proyectual de Gráfica Digital de la FADU-UNL con alrededor de 120 estudiantes de grado durante dos años consecutivos, para experimentar procesos de diseño colaborativos; en un libro hipermedial de la memoria de Wheelwright a partir de los aportes de sus ciudadanos; y en la exposición tecnológica INNOVAR 2013 destinada al público en general durante tres días completos. En cada caso el sistema adoptó diferentes configuraciones en relación a los usuarios y contextos, mediante la definición de tipos de archivos, utilidades y servicios diversos. Por ser una integración modular, permite reemplazar y/o agregar herramientas además de la actualización de las tecnologías ya integradas.

La evaluación aplicó observación participante (registrada con fotografías y videos), encuestas y entrevistas. En la encuesta del taller proyectual, el $91,67 \%$ de los estudiantes consideró positivo haber integrado este sistema al aula virtual del taller (en Moodle). En la exposición, el 93\% de los encuestados opinó que el sistema le resultó amigable y fácil de usar.

Actualmente se está desarrollando una interfaz de personalización a través de la cual los mismos usuarios podrán configurar el sistema según sus necesidades. Esta interfaz adaptativa permitirá

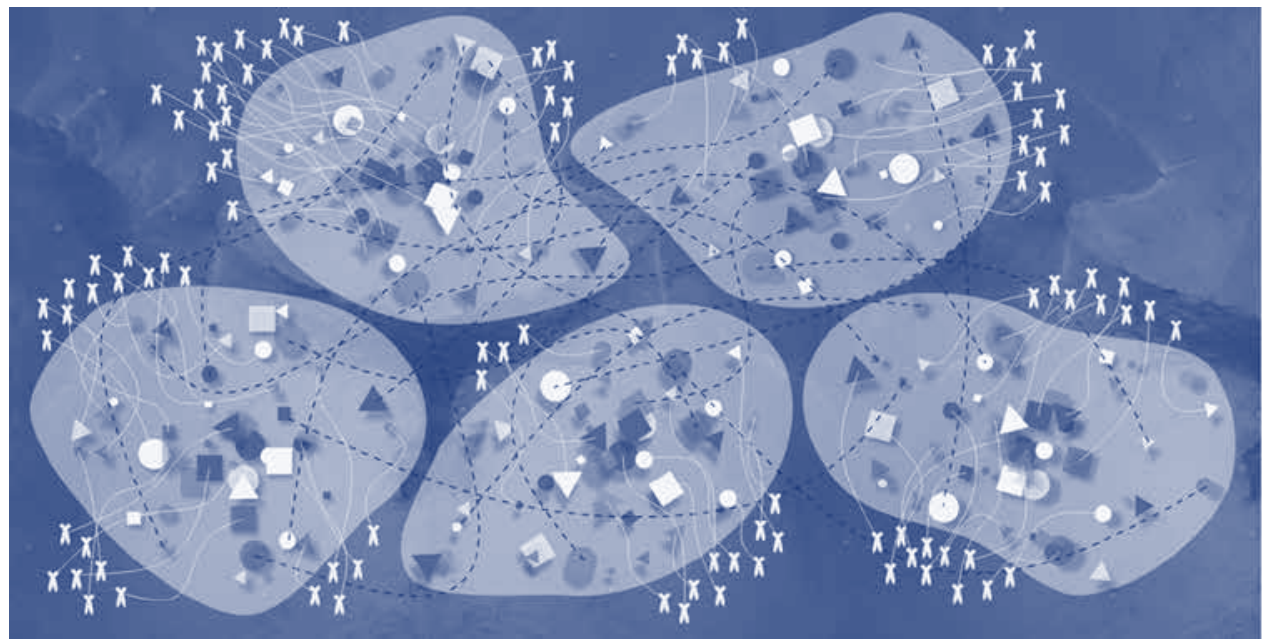

Diagrama operativo

Bases de Datos:

forma: tipo de archivo

tamaño: tamaño de archivo

color: cantidad de descargas alta

- media

baja

transparencia: tiempo de edición

x sujetos que aportan relaciones 
crear las tablas de las BD; definir los recursos de cada tabla en relación a las actividades o trabajos prácticos: los tipos de archivo, las relaciones entre ellos y los metadatos identificadores en los campos; configurar los elementos disponibles en los menús incorporando las aplicaciones y servicios web de uso frecuente necesarios; seleccionar las opciones de visualización, posición y tamaño de los elementos, colores, imagen fondo, etc.

\section{Conclusiones}

Una matriz evolutiva y flexible caracteriza este dispositivo hipermedial, una estructura de información modular distribuida en capas interconectadas, que puede reorganizarse dinámicamente, adquirir configuraciones diversas y propiciar trayectos complejos. Un entramado narrativo (Fig. 2) que provoca lecturas no-lineales en constante situación de suspenso, generadas a partir de tensiones multidireccionales del relato que articulan un flujo variable entre acontecimientos, líneas o superficies que son claves por su naturaleza abierta (Gausa y otros, 2001: 192).

En este contexto socio-técnico, es imprescindible contar con sistemas de AA que integren espacios virtuales públicos y privados, bases de datos y servicios, que nos acompañen a todos lados y nos permitan intercambios constantes. La narrativa transmedial de los espacios-interfaz en red con su gramática en convergencia, propone un relato narrado en tiempo real que utiliza diversos lenguajes y plataformas interconectadas para promover el diálogo y ofrecer múltiples puertas de entrada al conocimiento a través de un ámbito inmersivo y envolvente en el cual la imagen -como signo textual conceptualmente procesado- reafirma su poder en nuestra cultura visual.

\section{Agradecimientos}

Este trabajo es parte del proyecto de investigación CAI+D 2011 No356 "Diseño, desarrollo y evaluación de espacios-interfaz destinados a actividades de docencia, investigación y extensión en la universidad pública argentina”, subsidiado por la Universidad Nacional del Litoral, Santa Fe, Argentina.

\section{Referencias}

Gausa, M., Guallart, V., Müller, W., Soriano, F., Porras, F., y Morales, J. (2001). Diccionario Metápolis de arquitectura avanzada. Barcelona: Actar.

Giannetti, C. (1999). Ars Telemática: la estética de la intercomunicación. Mecad Electronic Journal, No 2.

Lévy, P. (2004). Inteligencia colectiva. Por una antropología del ciberespacio. Washington DC.

Lynch, K. (1984). La imagen de la ciudad. Barcelona: Gustavo Gili. Machado, A. (1996). El advenimiento de los Medios Interactivos. En La Ferla, J., Groisman, M. (Eds.), El Medio es el Diseño. Buenos Aires: Ed. Oficina de Publicacion del Ciclo Básico-UBA.

Manovich, L. (2006). El lenguaje de los nuevos medios, Buenos Aires: Paidós Comunicación.

Montagú, A., Groisman, M., Pimentel, D. (2004) Cultura Digital. Comunicación y Sociedad. Buenos Aires: Paidos.

Rancière, J. (2010). El Espectador Emancipado. Buenos Aires: Manantial.

Rodríguez Barros, D. (2012). Habitando los límites virtuales. Tesis doctoral. Universidad de Buenos Aires.

San Martín, P.; Guarnieri, G; Rodriguez, G; Bongiovani, P.; Sartorio, A. (2010). El dispositivo Hipermedial Dinámico Campus Virtual UNR. Rosario: Secretaría de Tecnologías Educativas y de Gestión de la UNR.

Schultz, M. (2006). Filosofía y Producciones Digitales. Buenos Aires: Alfagrama.

Simon, H. (2006). Las ciencias de lo artificial, Editorial Comare.

Thomas, H., Buch, A. (2008). Actos, Actores y Artefactos, Buenos Aires: Ed. Universidad Nacional de Quilmes. 